\title{
A pharmacokinetic interaction between cimetidine or ranitidine and lornoxicam
}

\author{
M. Ravic, I. Salas-Herrera, A. Johnston, P. Turner, K. Foley ${ }^{1}$ and \\ D.E. Rosenow ${ }^{2}$
}

Department of Clinical Pharmacology, St Bartholomew's Hospital, London ECIA 7BE, UK, ${ }^{1}$ Advisory Services (Clinical and General Ltd), 14 Harley Street, London W1N $2 A A, U K$ and ${ }^{2}$ Hafslund Nycomed Pharma, AG, Linz, Austria

\begin{abstract}
Summary: Cimetidine $\mathbf{4 0 0} \mathrm{mg}$ twice daily significantly increased serum concentrations and reduced apparent oral clearance of lornoxicam $8 \mathrm{mg}$ twice daily in 12 healthy volunteers. Ranitidine $150 \mathrm{mg}$ twice daily produced no significant changes in lornoxicam pharmacokinetics.
\end{abstract}

\section{Introduction}

Lornoxicam is a novel non-steroidal antiinflammatory drug (NSAID) which is currently undergoing clinical pharmacological evaluation, including studies of interactions with other drugs. ${ }^{1,2}$

Long-term treatment with NSAIDs may produce gastrointestinal symptoms for which histamine H2-receptor antagonists may be prescribed. Cimetidine has been shown to inhibit the hepatic metabolism of several drugs, ${ }^{3}$ and we have, therefore, carried out a study to investigate if cimetidine and an alternative H2-receptor antagonist, ranitidine, significantly influenced the pharmacokinetics of lornoxicam.

\section{Subjects and methods}

The study was open, randomized, and placebo controlled, and was designed to include 12 volunteers. Non-smoking volunteers of either sex, aged 21-28 years (average 23 years) and weighing $49-89 \mathrm{~kg}$ (average $68 \mathrm{~kg}$ ) participated after being found to be normal on medical, haematological and biochemical examinations, and free from evidence of drug abuse on urine screening. Sensitivity to NSAID, cimetidine or ranitidine, and history of indigestion, peptic ulcer, bronchial asthma, were exclusion criteria at recruitment. The protocol had been approved by the local ethics committee.

From days 1-20, lornoxicam $8 \mathrm{mg}$ tablets (Hafslund Nycomed Pharma) were taken with $100 \mathrm{ml}$ water at $09.00 \mathrm{~h}$ and $21.00 \mathrm{~h}$. From days

Correspondence: Professor P. Turner, C.B.E., M.D., B.Sc., F.R.C.P., F.F.P.M.

Accepted: 2 July 1993
$1-5,8-12$ and $15-19$ subjects also took one of the following in a balanced three-way cross-over design: cimetidine $400 \mathrm{mg}$ (Tagamet) or ranitidine $150 \mathrm{mg}$ (Zantac), or placebo tablet (distinguishable from the other treatments) with $100 \mathrm{ml}$ water at $08.00 \mathrm{~h}$ and $20.00 \mathrm{~h}$.

On days 6, 13 and 20 the $\mathrm{H} 2$-receptor antagonist or placebo was taken fasting at $08.00 \mathrm{~h}$ and lornoxicam $8 \mathrm{mg}$ at $09.00 \mathrm{~h}$. Venous blood samples were taken from a cannula before, and at $0.5,1,1.5,2,3$, $4,6,8,10$ and 12 hours after the lornoxicam dose for pharmacokinetic estimation. Lornoxicam serum concentrations were measured by high performance liquid chromatography with ultraviolet detection. ${ }^{4}$ Serum concentrations were fitted to a two-compartment model using the computer program 'STRIPE', 5 and standard pharmacokinetic parameters were derived from the log serum concentration-time curves constructed for each subject. A two-way analysis of variance was used to detect statistically significant differences between the three treatments, the two factors being subject and treatment. Friedman analysis of variance for non-parametric data was used to compare $T_{\max }$ values.

\section{Results}

Administered drugs were generally well tolerated and no marked adverse effects were recorded except in one subject who complained of severe gastric irritation after 6 days treatment with lornoxicam and had to withdraw from the study. $\mathrm{He}$ was replaced by another volunteer, and his symptoms disappeared over the next 2 weeks during which he was treated with ranitidine. One further subject complained of transient indigestion but did 
Table I Lornoxicam pharmacokinetic parameters (mean \pm s.d.) when given in combination with placebo, cimetidine or ranitidine $(n=12)$

\begin{tabular}{lllll}
\hline Parameter & Placebo & Cimetidine & Ranitidine & $\begin{array}{l}\text { Analysis of } \\
\text { variance }\end{array}$ \\
\hline $\begin{array}{l}C_{\max }(\mu \mathrm{g} / 1) \\
\text { s.d. }\end{array}$ & 1,135 & 1,448 & 1,093 & $<0.05$ \\
$T_{\max }$ (hours) & 555 & 596 & 454 & \\
(median) & 2.00 & 2.00 & 1.50 & $\mathrm{NS}$ \\
Range & $1.00-4.00$ & $1.00-3.00$ & $0.50-4.00$ & \\
AUC (mg/1 hour) & 6,410 & 6,963 & 5,734 & $<0.05$ \\
s.d. & 3,056 & 2,382 & 2,318 & \\
& & & & \\
$t_{1 / 2}($ hours) & 4.20 & 3.17 & 3.94 & $\mathrm{NS}$ \\
s.d. & 1.22 & 0.99 & 1.16 & \\
Cl (ml/minute) & 24.36 & 21.45 & 26.46 & $<0.05$ \\
s.d. & 9.28 & 7.80 & 9.09 & \\
$V_{\mathrm{d}}(1)$ & 8.67 & 5.92 & 8.64 & $<0.05$ \\
s.d. & 3.55 & 2.57 & 3.36 & \\
\hline
\end{tabular}

NS = not significant; $C_{\max }=$ peak serum concentration; $T_{\max }=$ time to peak concentration; $\mathrm{AUC}=$ concentration time curve from 0 to 12 hours; $t_{1 / 2}=$ elimination half-life; $\mathrm{Cl}=$ apparent oral clearance (dose/AUC); $V_{\mathrm{d}}=$ apparent volume of distribution $(\mathrm{Cl} /$ elimination rate constant).

not ask to withdraw and completed the study. Another subject complained of transient somnolence, but completed the study.

Pharmacokinetic parameters of the 12 completing volunteers are shown in Table I. A clear interaction is seen between cimetidine and lornoxicam, with significantly increased peak serum concentration $\left(C_{\max }\right)$ and concentration time curve from 0 to 12 hours (AUC) values, and reduced clearance and volume of distribution of lornoxicam when receiving cimetidine, but not ranitidine.

The subject withdrawn from the study on day 6 was found to have been taking lornoxicam plus ranitidine. On that day, his $C_{\max }$ was $6,589 \mathrm{mg} / 1$, and AUC $56,426 \mathrm{mg} / 1$ hour. Comparison with Table I shows that these values greatly exceeded those of the 12 volunteers who completed the study.

\section{References}

1. Ravic, M., Johnston, A. \& Turner, P. Clinical pharmacological studies of some possible interactions of lornoxicam with other drugs. Postgrad Med J 1990, 66 (Suppl 4): S30-S34.

2. Turner, P. \& Johnston, A. Clinical pharmacokinetic studies with lornoxicam. Postgrad Med J 1990, 66 (Suppl 4): S28-S29.

3. Griffin, J.P., D'Arcy, P.F. \& Spiers, C.J. A Manual of Adverse Drug Interactions, 4th ed. Wright, London, 1988, pp. 19-20.

4. Ankier, S.I., Brimelow, A.E., Crome, P. et al. Chlortenoxicam pharmacokinetics in young and elderly human volunteers. Postgrad Med J 1988, 64: 752-754.

\section{Discussion}

This study has shown that cimetidine inhibits the excretion of lornoxicam, as it does many other drugs. ${ }^{3}$ Lornoxicam is extensively metabolized in man, little or no unchanged drug being detected in the urine. ${ }^{2}$ A major metabolic pathway is hydroxylation to $5^{\prime}$-hydroxylornoxicam, and it may be this pathway that is inhibited by cimetidine. It is also possible that a defect in this pathway is responsible for the high $C_{\max }$ and AUC value of lornoxicam in the one subject who had to be removed from the study. His values are similar to those that we have seen in three subjects in other studies which we have carried out. ${ }^{2}$ A study in slow metabolizers of debrisoquine and mephenytoin, however, has failed to show any influence on lornoxicam pharmacokinetics. $^{6}$

5. Johnson, A. \& Wollard, R.C. STRIPE: an interactive computer program for the analysis of drug pharmacokinetics. Pharmacol Meth 1983, 9: 193-199.

6. Stroibnig, H. Proceedings of the 5th European Congress of Biopharmaceutics and Pharmacokinetics, Brussels, 1993. 